\title{
Sosyal Bilgiler Dersinde Öğrenci Merkezli Öğretme-Öğrenme Süreçlerinin Etkililiği: Bir Meta Analiz Çalışmasıı ${ }^{1}$ \\ The Effectiveness of Student-Centered Teaching- Learning Processes in the Social Studies: A Meta-Analysis Study
}

Şefik YAŞAR

Anadolu University, Turkey

syasar@anadolu.edu.tr

\author{
Tuba ÇENGELCİ KÖSE \\ Anadolu University, Turkey \\ tubacengelci@anadolu.edu.tr
}

\author{
Nur Leman GÖZ \\ Anadolu University, Turkey \\ nlgoz@anadolu.edu.tr
}

\section{Ömür GÜRDOĞAN BAYIR \\ Anadolu University, Turkey \\ ogurdogan@anadolu.edu.tr}

\begin{abstract}
Özet
Sosyal Bilgiler öğretiminin gelişiminde, öğrenme ve öğretme süreçleriyle ilgili araştırma bulguları yol gösterici nitelik taşımaktadır. $\mathrm{Bu}$ nedenle, eğitim kurumlarında öğretmeöğrenme sürecinde çeşitli yöntem, teknik, materyal ve yaklaşımların etkililiğini sınayan araştırmaların yapılması son derece önemlidir. Bu araştırmaların bulguları Sosyal Bilgiler dersinde akademik başarıyı artırmaya yardımcı olan öğretim yöntem ve tekniklerinin belirlenmesi bakımından önemlidir. Araştırmanın amacı meta analiz yöntemiyle, ilköğretim Sosyal Bilgiler derslerinde kullanılan öğrenci merkezli öğretme-öğrenme süreçlerinin akademik başarıya etkisini ortaya koymaktır. Bu kapsamda, 2005 yılı sonrasında Türkiye'de yapılan ve Yükseköğretim Kurulu Ulusal Dijital Tez arşivinde yer alan toplam 52 yüksek lisans ve doktora tezi araştırmanın verilerini oluşturmuştur. Araştırmada verilerin analizinde Comprehensive Meta Analysis (CMA) programından yararlanılmıştır. Verilerin analizinde işlem etkisi meta-analizi kullanılmıştır. Araştırmaya katılan çalışmaların tümünün akademik başarıya artırmada pozitif bir etkiye sahip olduğu görülmüştür. Araştırmada elde edilen
\end{abstract}

\footnotetext{
${ }^{1}$ Bu makale 7-9 Mayıs 2014 tarihinde Gaziantep’te düzenlenen 3. Ulusal Eğitim Programları ve Öğretim Kongresi'nde sözlü bildiri olarak sunulan çalışmaya dayalı olarak hazırlanmıştır.
} 
sonuçlar Sosyal Bilgiler dersinde öğretim sürecinde kullanılan öğrenci merkezli yaklaşım, yöntem, teknik ve materyallerin öğrenci başarısını artırdığını ortaya koymaktadır.

Anahtar Kelimeler: Sosyal Bilgiler, Öğrenci merkezli öğretim, Meta-analiz

\begin{abstract}
Research findings about teaching-learning process play important role in developing Social Studies teaching. Therefore, studies should be conducted to investigate effectiveness of different teaching methods and techniques in educational institutions. Findings of these studies are significant to figure out teaching methods and techniques which may have a positive effect on academic achievement. Purpose of this study is to analyze the effect of student-centered teaching learning process on academic achievement in the Social Studies course via meta-analysis method. Data of the study were obtained from 52 Master and $\mathrm{PhD}$ theses which were submitted to the YÖK National Digital Thesis/Dissertation Archives after 2005 in Turkey. Comprehensive Meta-Analysis (CMA) software was used to conduct the meta-analysis. The present study used "study effect" meta-analysis for the analysis of the data. Findings of the study revealed that student-centered teaching approaches, methods, techniques, and materials had a positive effect on academic achievement in the Social Studies course.
\end{abstract}

Keywords: Social Studies, Student-centered teaching, Meta-analysis

\title{
Giriş
}

Sosyal Bilgiler dersi öğrencilerin ilkokul yıllarında karşılaştığı ve yaşamında gereksinim duyacağı temel bilgi, beceri, değer ve tutumları öğrendiği bir derstir. Çeşitli disiplinleri içinde barından bu ders öğrencilere birey ve toplumu ilgilendiren her konuda bakış açısı kazandırmaktadır. $\mathrm{Bu}$ nedenle, toplumların gereksinim duyduğu nitelikli bireylerin yetiştirilmesinde Sosyal Bilgiler önemli rol oynamaktadır.

Sosyal Bilgiler yerelden evrensele toplumları, bu toplumların özelliklerini ve kültürlerini, bu toplumlarda vatandaşlığın doğasını incelemeyi ve anlamayı amaçlamaktadır. $\mathrm{Bu}$ derste öğrenciler değişim, kültür, çevre, güç gibi sosyal bilimlerle ilgili anahtar kavramları öğrenmektedirler (Schmidt, 2007). Temel vurgusunda vatandaşlık eğitimi olan Sosyal Bilgiler dersinde bunun için gerekli bilgi, beceri ve değerlerin dengeli biçimde kazandırılması gerekmektedir. Sosyal Bilgiler öğrencileri iyi bir vatandaş olarak yetiştirmek için sosyal bilimlerden ilgili bilgi, beceri ve tutumları bütünleştirmektedir (Obenchain ve Morris, 2011; 
Seefeldt ve diğerleri, 2010). Sosyal Bilgiler dersinin amaçlarına ulaşabilmesi Sosyal Bilgiler dersinde gerçekleştirilen öğretme-öğrenme sürecinin niteliği ile doğru orantılıdır. Sosyal Bilgiler dersinde öğrenci etkinliğine dayalı olmayan uygulamalar öğrencilerin bu derse ilişkin tutumlarını olumsuz yönde etkileyebilir. Bu nedenle, bu dersin öğretiminde öğrenciyi etkin hale getirecek, öğretme-öğrenme sürecinin verimli geçmesini ve belirlenen kazanımlara ulaşmayı sağlayacak yöntem-teknik, araç-gereç ve toplumsal kaynaklardan yararlanılmalıdır (Gürdoğan Bayır, 2010).

Öğrenci merkezli öğrenme ve öğretim büyük ölçüde sosyal yapılandırmacılık ile desteklenmektedir. Öğrencinin fiziksel dünya ile doğrudan etkileşime girerek, deneyim kazanarak ve diğer bireylerle etkileşim kurarak kendi anlamını oluşturmasını savunan görüşlere dayanmaktadır (Deboer, 2002). Öğrencilerin bireysel ilgi, gereksinim ve yeteneklerine dayalı olarak anlam ve anlayışı oluşturmalarını destekleyen öğrenci merkezli eğitim aynı zamanda demokratik eğitimin amaçlarına ulaşma bakımından da çok önemli bir katkı sağlamaktadır (Yılmaz, 2009). Dewey (2008) çocuğun istek ve gereksinimlerinin merkeze alınmadığı, öğretmen ve ders kitabının merkezde olduğu ve dinleme kuralına dayalı bir ortam yerine çocuğun merkezde olduğu bir okul ortamından söz etmektedir. Sosyal yapılandırmacılığın egemen olduğu bir öğrenme ortamında ise öğretmenin görevi öğrenmeyi desteklemektir. Sosyal yapılandırmacı öğretmenler sosyal bilgiler dersinde öğrencileri anlamak için yolculuğa çıkmış gezginler olarak görürler. Onların görevi bu yolculukta öğrencilere rehberlik etmektir. Öğrenme sosyal bir ortamda meydana gelir. Bu nedenle öğrenciler bilgiyi birlikte inşa eden öğrenenler topluluğu olarak görülmelidir (Maxim, 2006).

Russell'ın (2010) 21. yüzyılda Sosyal Bilgiler öğretimini öğretmen görüşleri doğrultusunda incelediği araştırmasının bulguları Sosyal Bilgilerde teori ve uygulama arasında büyük bir boşluk olduğunu, öğretmenlerin anlatım yöntemini tercih ettiklerini, ders kitabını birinci kaynak olarak gördüklerini, Sosyal Bilgiler dersinin amaçlarına ulaşmak için potansiyellerini tam olarak kullanmadıklarını ortaya koymaktadır. Öğrencileri demokratik bir toplumun etkin vatandaşları olarak yetiştirme görevini üstlenen Sosyal Bilgiler dersinde yapılandırmacı yaklaşım ve öğretim uygulamaları 1şığında düzenlenecek öğrenci merkezli öğretim uygulamaları dersin amaçlarına ulaşmasını kolaylaştırabilir. Bu alanda yapılan araştırmaların sonuçları eğitimciler açısından yol gösterici nitelik taşıyabilir. 
Alanyazında Sosyal Bilgiler dersinde yapılandırmacı öğrenme yaklaşımının (Ünal ve Çelikkaya, 2009) ve yapılandırmacı yaklaşıma ait öğretim uygulamalarının (Avşar ve Alkış, 2007; Deveci, 2003; Gültekin, 2005; İbrahimoğlu ve Öztürk, 2013) akademik başarıya etkisini, aktif öğrenme tekniklerinin demokratik tutumlara ve öğrenci başarısına etkisini (Duman ve diğerleri, 2008) inceleyen çeşitli çalışmalar bulunmaktadır. Sosyal Bilgiler öğretiminin gelişiminde, öğrenme ve öğretme süreçleriyle ilgili araştırma bulguları yol gösterici nitelik taşımaktadır. Bu nedenle, eğitim kurumlarında çeşitli yaklaşım, yöntem, teknik ve materyallerin etkililiğini sınayan araştırmaların yapılması son derece önemlidir. Alanyazında bu çalışmaların birlikte incelendiği bir çalışmaya rastlanmamıştır. Bu çalışma sözü edilen gereksinimden yola çıkarak bir meta analiz çalışması biçiminde desenlenmiştir. Araştırma kapsamında yapılandırmacı yaklaşım ve yapılandırmacı yaklaşımın öğretim uygulamaları olarak kabul edilen işbirliğine dayalı öğrenme ve proje tabanlı öğrenme (Yaşar, 2012) yöntemlerinin yanı sıra beyin temelli öğrenme, çoklu zekâ kuramı, buluş yoluyla öğrenme, harmanlanmış öğrenme, araştırmaya dayalı öğrenme, aktif öğrenme ve bilgisayar destekli öğrenme gibi öğrenci etkinliğine dayalı öğrenme yaklaşımlarını inceleyen çalışmalar meta analiz sürecine dâhil edilmiştir. Araştırmanın, sözü edilen yöntemlerden Sosyal Bilgiler dersinde akademik başarıya etkisi olanları ortaya koyma bakımından yararlı olacağı düşünülmektedir. $\mathrm{Bu}$ bağlamda, araştırmanın amacı meta analiz yöntemiyle, ilköğretim Sosyal Bilgiler derslerinde kullanılan öğrenci merkezli öğretim süreçlerinin akademik başarıya etkisini ortaya koymaktır.

\section{Yöntem}

$\mathrm{Bu}$ araştırmada ilköğretim Sosyal Bilgiler derslerinde kullanılan öğrenci merkezli öğretmeöğrenme süreçlerinin akademik başarıya etkisini ortaya koymak amacıyla meta-analiz yöntemi kullanılmıştır. Araştırmada meta-analiz yöntemi, Sosyal Bilgiler alanında öğrenci merkezli öğretim yöntemlerinin etkisine ilişkin çok sayıda çalışma bulunması nedeniyle tercih edilmiştir.

Günümüzde bilimsel çalışmaların artması ve bu araştırmaların amaçlarının hedef kitlelere ulaşmasında güçlük çekilmesi nedeniyle bilgilerin bir çatı altında toplanması, tekrar bir analiz sürecinden geçirilmesi ve yeni kararlara varılması gereksinimini doğurmuş ve meta-analiz çalışmaları ortaya çıkmıştır (Sağlam ve Yüksel, 2007; Akgöz, Ercan ve Kan, 2004). Metaanaliz çalışmaların verilerini özetleyen bir yöntemdir (Minton, 2005'ten akt. Çelik, 2013, s.50). Başka bir deyişle, meta-analiz diğer analizlerin analizi yani diğer çalışmaların sonuçlarını tutarlı ve uyumlu bir şekilde bir araya getirmedir. (Cohen, 1988). Meta-analizde 
öncelikle araştırmaya konu olacak çalışmaların betimsel analizi yapılmakta, daha sonra ise bulgular istatistiksel olarak birleştirilmektedir. $\mathrm{Bu}$ aşamalardan sonra ise uygun istatistiksel model seçilmelidir (Topçu, 2009). Meta-analizde sabit etkiler modeli ve rasgele etkiler modelinden yararlanılmaktadır. Sabit etkiler modeli tüm çalışmaların aynı olduğu durumlarda kullanılmaktadır. Rasgele etkiler modelinde etki büyüklüğü çalışmadan çalışmaya farklılık göstermektedir (Borenstain, Hedges ve Rothstein, 2007'den akt. Çelik, 2013, ss.47-48). Çalışmalardan bu modellerden hangisinin kullanılacağına homojen testi ile karar verilmektedir.

\section{Verilerin Toplanması}

Araştırmanın verilerini Türkiye'de yapılan yüksek lisans ve doktora tezleri oluşturmuştur. Yüksek lisans ve doktora tezlerine ulaşmak için Yükseköğretim Kurulu Ulusal Tez Merkezi’nin gelişmiş arama bölümüne "Sosyal Bilgiler”, “Akademik Başarı” ve "Erişiı” sözcükleri yazılmıştır. Bu kapsamda toplam 94 çalışmaya ulaşılmıştır. Belirlenen dâhil edilme ölçütleri 1şığında ise 52 çalışma analize tabi tutulmuştur. Araştırmada dâhil edilme ölçütleri olarak çalışmaların 2005'ten sonra yapılması, çalışmalarda deneysel yöntemin kullanılması, çalışmaların deney ve kontrol grubu için aritmetik ortalama, standart sapma ve örneklem büyüklüklerini içermesi, analizlerin t testi ile yapılmış olması ve çalışmalardaki ön testler arasında anlamlı bir farklılı̆̆ın bulunmaması belirlenmiştir. Bu çalışmada makale, bildiri ve araştırma raporları kapsam dışında tutulmuştur. Araştırma kapsamında yer alan çalışmalar bir kodlama formu kullanılarak kodlanmıştır. Kodlama formunda çalışmanın yazarı, yılı, hangi üniversitede yapıldığı, türü, hangi sınıf düzeyinde gerçekleştirildiği, çalışmada kullanılan yöntem, deney ve kontrol grubundaki örneklem büyüklüğü, son test puanları ve standart sapmaları yer almaktadır. Araştırmada analize alınan çalışmalar EK1'de sunulmuştur. Çalışmalara ilişkin bilgiler Tablo 1'de sunulmuştur.

Tablo 1

Çalışmalara ilişkin bilgiler

\begin{tabular}{lll}
\hline Değişken & & $\mathrm{f}$ \\
\hline \multirow{4}{*}{ Çalışmanın yapıldığı yıl } & 2005 & 4 \\
\cline { 2 - 3 } & 2006 & 6 \\
\cline { 2 - 3 } & 2007 & 6 \\
\cline { 2 - 3 } & 2008 & 9 \\
\cline { 2 - 3 } & 2009 & 10 \\
\cline { 2 - 3 } & 2010 & 3 \\
\cline { 2 - 3 } & 2011 & 4 \\
\hline
\end{tabular}


Anadolu Journal of Educational Sciences International, January 2015, 5(1)

\begin{tabular}{|c|c|c|}
\hline & 2013 & 1 \\
\hline \multirow{2}{*}{ Çalışmanın türü } & Yüksek lisans & 45 \\
\hline & Doktora & 7 \\
\hline \multirow{24}{*}{ Çalışmanın yapıldığı üniversite } & Gazi Üniversitesi & 10 \\
\hline & Niğde Üniversitesi & 3 \\
\hline & Karadeniz Teknik Üniversitesi & 1 \\
\hline & Uludağ Üniversitesi & 1 \\
\hline & Selçuk Üniversitesi & 6 \\
\hline & F1rat Üniversitesi & 4 \\
\hline & Ankara Üniversitesi & 1 \\
\hline & Çanakkale On Sekiz Mart Üniversitesi & 2 \\
\hline & Mustafa Kemal Üniversitesi & 1 \\
\hline & Anadolu Üniversitesi & 3 \\
\hline & Sttk1 Koçman Üniversitesi & 1 \\
\hline & Dokuz Eylül Üniversitesi & 3 \\
\hline & İnönü Üniversitesi & 1 \\
\hline & Zonguldak Karaelmas Üniversitesi & 2 \\
\hline & Yeditepe Üniversitesi & 2 \\
\hline & Aksaray Üniversitesi & 1 \\
\hline & Kafkas Üniversitesi & 2 \\
\hline & Afyon Kocatepe Üniversitesi & 1 \\
\hline & Hacettepe Üniversitesi & 1 \\
\hline & Abant İzzet Baysal Üniversitesi & 2 \\
\hline & Gaziosmanpaşa Üniversitesi & 1 \\
\hline & Çukurova Üniversitesi & 1 \\
\hline & Akdeniz Üniversitesi & 1 \\
\hline & Celal Bayer Üniversitesi & 1 \\
\hline \multirow{4}{*}{ Çalışmanın yapıldığı sınıf düzeyi } & 4. sinif & 10 \\
\hline & 5. sinif & 9 \\
\hline & 6. sinif & 20 \\
\hline & 7. sinif & 13 \\
\hline \multirow{22}{*}{ Çalışmada kullanılan öğrenci merkezli yöntem } & Portfolyo kullanımı & 1 \\
\hline & Materyal kullanımı & 5 \\
\hline & Coğrafi bilgi sistemleri & 3 \\
\hline & Kavram karikatürü & 1 \\
\hline & Çoklu zekâ kuramı & 6 \\
\hline & Yapılandırmacı kuram & 2 \\
\hline & Alt1 şapkalı düşünme tekniği & 1 \\
\hline & Drama & 3 \\
\hline & Aktif öğrenme & 3 \\
\hline & Araştırmaya dayalı öğrenme & 1 \\
\hline & Öykü ile öğretim & 2 \\
\hline & İşbirliğine dayalı öğrenme & 5 \\
\hline & Beyin temelli öğrenme & 1 \\
\hline & Proje tabanlı öğrenme & 5 \\
\hline & Planlama ve yazma becerileri & 1 \\
\hline & Yansitıcı düşünme & 1 \\
\hline & Buluş yoluyla öğrenme & 1 \\
\hline & Bilgisayar destekli öğrenme & 3 \\
\hline & Dizgeli eğitim & 1 \\
\hline & Gezi-gözlem & 1 \\
\hline & Rol oynama & 1 \\
\hline & Sözlü tarih & 1 \\
\hline
\end{tabular}




\begin{tabular}{lll}
\hline & Harmanlanmış öğrenme & 2 \\
\cline { 2 - 3 } & Sanal müzelerden yararlanma & 1 \\
\hline Toplam & & $\mathbf{5 2}$ \\
\hline
\end{tabular}

Tablo 1'de görüldüğü gibi, analize dâhil edilen çalışmaların 9'u 2009 yılında yapılmıştır. Bu çalışmaların 45'i yüksek lisans düzeyindeyken, 7'si doktora düzeyindedir. Ayrıca yine çalışmaların 10'u Gazi Üniversitesi'nde, 6'sı Selçuk Üniversitesi'nde, 4'ü ise Firat Üniversitesi'nde yapılmıştır. Çalışmalar en fazla 6. sınıf $(\mathrm{f}=20)$ öğrencileri ile gerçekleştirilmiş, yöntem olarak ise en fazla çoklu zekâ kuramı $(\mathrm{f}=6)$ kullanılmıştır.

Meta-analize getirilen en büyük eleştirilerden biri dâhil edilen çalışmaların yanlı çıkma düşüncesidir. Bu yanlılığının ortadan kaldırılabilmesi için etki büyüklügünü sıfır yapacak kaç tane çalışmanın analize dâhil edilmesi gerektiğinin hesaplanmasıdır (Özcan, 2008). Bu sayı (fail safe N) meta-analiz araştırmasında bulunan etki büyüklügünü geçersiz hale getirecek kadar zıt yönlü değerlere sahip çalışma sayısını göstermektedir. Alanyazında bu sayıda çalışma bulunduğunda meta-analiz bulguları geçersiz olacaktır (Okursoy Günhan, 2009). Araştırmada elde edilen bu sayı Rosenthal yöntemi ile 2056'dır. 52 çalışmanın dâhil edildiği bu araştırmanın bulgularının geçersiz sayılabilmesi için alanyazında 2056 tane zıt bulgulara sahip çalışmanın olması gerekmektedir. Bu çalışma sayısı Orwin yöntemi kullanıldığında 1165 olmuştur. $\mathrm{Bu}$ sonuçlara göre araştırmanın meta-analiz sonuçlarının güvenilir olduğu söylenebilir. Meta-analiz çalışmalarında yayın yanlılığına huni grafiğine bakılarak da karar verilebilir. Bu araştırmanın huni grafiği Şekil 1'de gösterilmiştir.

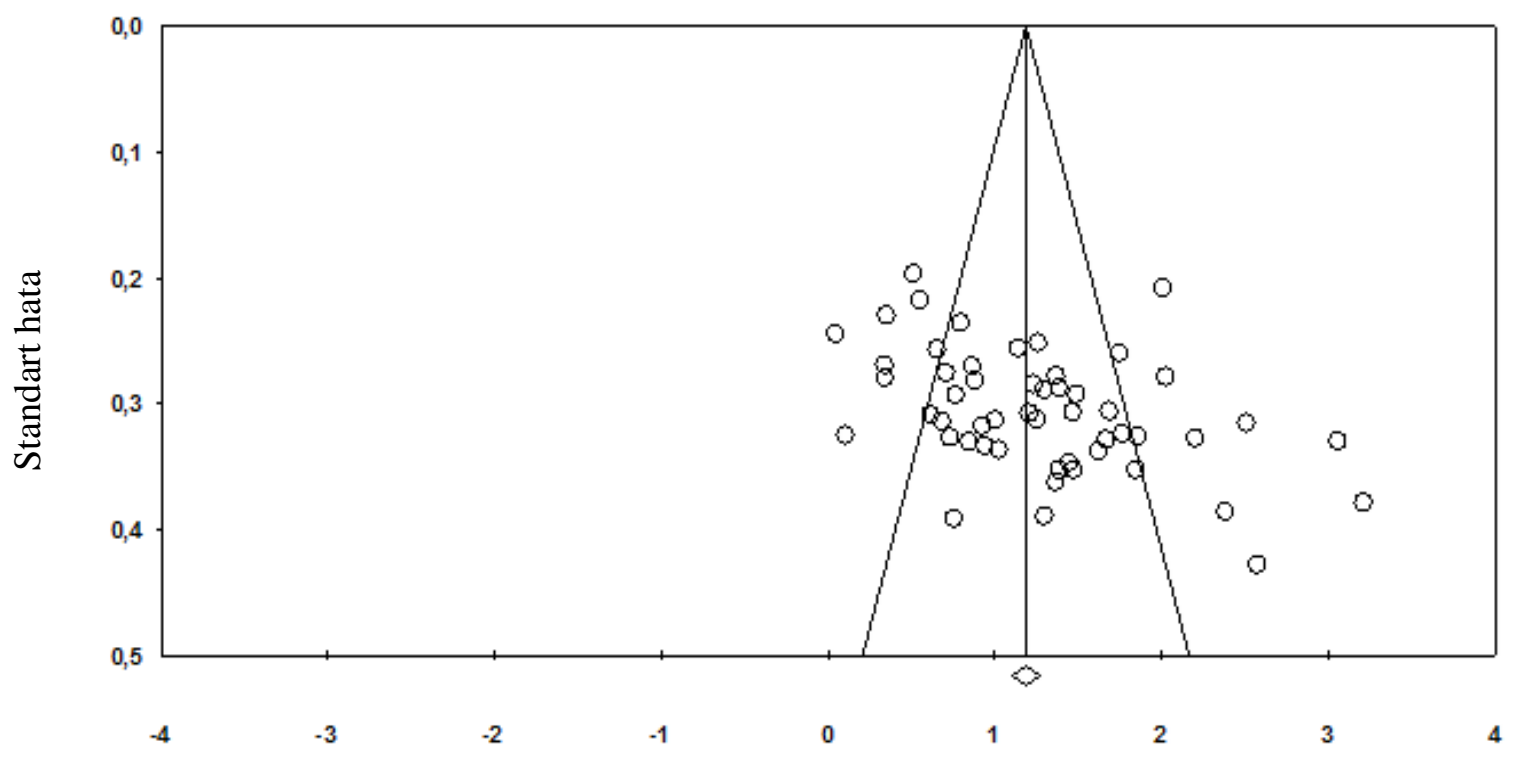

Hedge's g

Şekil 1. Araştırmaya ilişkin huni grafiği 
Şekil 1'deki grafikte geniş alanda bir saçılmanın olmadığı görülmektedir. Bu saçılmanın olmamasının nedeni yayın yanlılığının bulunmamasıdır (Üstün, 2012). Başka bir deyişle, araştırmanın sonuçlarının huni grafiğine göre de güvenilir olduğu söylenebilir.

\section{Verilerin Analizi}

Araştırmada verilerin analizinde Comprehensive Meta Analysis (CMA) programından yararlanılmıştır. Verilerin analizinde işlem etkisi meta-analizi kullanılmıştır. Etki büyüklüğünün deney ve kontrol gruplarına bağlı olarak hesaplandığı bu analizde etki büyüklüğü gruplar arasındaki ortalama fark anlamına gelmektedir (Malofeeva, 2005'ten akt. Çelik, 2013, s.58). İşlem etkililiğinde standartlaştırılmış etki büyüklüğü “d” ya da "g” harfiyle gösterilmektedir (Şahin, 2005). Bu araştırmada etki büyüklüğü hesaplamada "Hedge’s g” kullanılmıştır. Araştırmada etki büyüklüklerinin yorumlanmasında ise şu sınıflandırmadan yararlanılmıştır (Thalheimer ve Cook, 2002):

- $\quad-0.15-0.15$ önemsiz düzeyde

- 0.15-0.40 küçük düzeyde

- $0.40-0.75$ orta düzeyde

- $0.75-1.10$ geniş düzeyde

- $1.10-1.45$ çok geniş düzeyde

- 1.45 - mükemmel düzeyde

\section{Bulgular ve Yorum}

Öğretim sürecinde kullanılan farklı yöntem, teknik, yaklaşım ve materyallerin Sosyal Bilgiler dersinde akademik başarıya etkisini belirlemeyi amaçlayan bu araştırmada etki büyüklüklerinin hesaplanmasında deney kontrol gruplarının örneklem büyüklükleri, standart sapmaları ve son test puan ortalamaları kullanılmıştır. Buna göre, araştırmaya dâhil edilen çalışmaların birleştirilmemiş etki büyüklükleri, güven aralıkları ve çalışma ağırlıkları Tablo 2'de gösterilmiştir. 
Anadolu Journal of Educational Sciences International, January 2015, 5(1)

Tablo 2.

Çalışmaların birleştirilmemiş etki büyüklükleri, güven aralığl ve çalışmanın ă̆ırlı̆̆l

\begin{tabular}{|c|c|c|c|c|c|}
\hline \multirow[b]{2}{*}{ Yazar } & \multirow[b]{2}{*}{$\begin{array}{l}\text { Etki } \\
\text { büyüklüğü }\end{array}$} & \multicolumn{2}{|c|}{ Güven aralığı } & \multirow[b]{2}{*}{$\begin{array}{l}\text { Çalışma } \\
\text { ağırlığı } \\
\text { (Sabit } \\
\text { etkiler) }\end{array}$} & \multirow[b]{2}{*}{$\begin{array}{l}\text { Çalışma } \\
\text { ağırlığı } \\
\text { (rasgele } \\
\text { etkiler) }\end{array}$} \\
\hline & & $\begin{array}{l}\mathbf{\Xi} \\
\stackrel{5}{*}\end{array}$ & 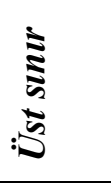 & & \\
\hline Aladağ, 2007 & 0,911 & 0,299 & 1,522 & 1,66 & 1,90 \\
\hline Alkan, 2010 & 2,006 & 1,465 & 2,547 & 2,12 & 1,99 \\
\hline Ateş, 2007 & 0,829 & 0,195 & 1,463 & 1,54 & 1,87 \\
\hline Avc1, 2009 & 1,735 & 1,230 & 2,239 & 2,43 & 2,03 \\
\hline Avşar, 2010 & 1,370 & 0,814 & 1,926 & 2,00 & 1,97 \\
\hline Ayazcan, 2005 & 0,755 & 0,190 & 1,321 & 1,94 & 1,96 \\
\hline Aykaç, 2008 & 1,1148 & 0,856 & 2,041 & 1,76 & 1,92 \\
\hline Babacan, 2006 & 1,473 & 0,907 & 2,039 & 1,93 & 1,96 \\
\hline Bağc1, 2009 & 0,104 & $-0,519$ & 0,727 & 1,60 & 1,88 \\
\hline Bulut, 2010 & 1,667 & 1,075 & 2,258 & 1,77 & 1,92 \\
\hline Çalıșkan, 2008 & 0,855 & 0,333 & 1,378 & 2,27 & 2,01 \\
\hline Çalışkan Fındık, 2005 & 3,175 & 2,442 & 3,908 & 1,15 & 1,74 \\
\hline Çelebi, 2006 & 0,672 & 0,068 & 1,276 & 1,70 & 1,91 \\
\hline Çengelci, 2005 & 0,719 & 0,91 & 1,346 & 1,57 & 1,88 \\
\hline Çiftçi, 2006 & 1,446 & 0,769 & 2,124 & 1,35 & 1,81 \\
\hline Daşdemir, 2013 & 1,999 & 1,593 & 2,405 & 3,76 & 2,15 \\
\hline Erdoğan, 2009 & 0,870 & 0,326 & 1,414 & 2,09 & 1,98 \\
\hline Ersözlü, 2008 & 1,250 & 0,762 & 1,738 & 2,60 & 2,05 \\
\hline Eskitürk, 2009 & 1,354 & 0,816 & 1,891 & 2,14 & 1,99 \\
\hline F1rat, 2008 & 3,031 & 2,392 & 3,671 & 1,51 & 1,86 \\
\hline Göçmen, 2007 & 1,817 & 1,138 & 2,496 & 1,34 & 1,81 \\
\hline Gökgöz, 2010 & 0,338 & $-0,182$ & 0,858 & 2,29 & 2,01 \\
\hline Göncüoğlu, 2010 & 0,989 & 0,386 & 1,592 & 1,70 & 1,91 \\
\hline Görer, 2008 & 0,549 & 0,126 & 0,972 & 3,46 & 2,13 \\
\hline Gülsoy, 2010 & 0,349 & $-0,097$ & 0794 & 3,12 & 2,10 \\
\hline Karaduman, 2005 & 1,009 & 0,362 & 1,655 & 1,48 & 1,85 \\
\hline Karakoç, 2006 & 1,280 & 0,721 & 1,838 & 1,98 & 1,97 \\
\hline Kartal, 2009 & 2,484 & 1,873 & 3,096 & 1,66 & 1,90 \\
\hline Kaya, 2009 & 0,923 & 0,283 & 1,563 & 1,51 & 1,86 \\
\hline Keser, 2012 & 2,175 & 1,542 & 2,808 & 1,54 & 1,87 \\
\hline Kiy Can, 2010 & 0,606 & 0,012 & 1,200 & 1,76 & 1,92 \\
\hline Koç, 2008 & 1,360 & 0,683 & 2,038 & 1,35 & 1,81 \\
\hline Mergen, 2011 & 1,340 & 0,645 & 2,035 & 1,28 & 1,79 \\
\hline Öner, 2007 & 1,643 & 1,009 & 2,276 & 1,54 & 1,87 \\
\hline Öntaş, 2010 & 1,595 & 0,945 & 2,246 & 1,46 & 1,85 \\
\hline Özkan, 2009 & 0,701 & 0,168 & 1,233 & 2,18 & 2,00 \\
\hline Öztürk, 2011 & 0,046 & $-0,0428$ & 0,520 & 2,76 & 2,07 \\
\hline Salur, 2009 & 1,267 & 0,524 & 2,011 & 1,12 & 1,72 \\
\hline Sar1, 2007 & 2,343 & 1,600 & 3,086 & 1,12 & 1,72 \\
\hline Sarıtepeci, 2012 & 0,510 & 0,128 & 0,893 & 4,23 & 2,18 \\
\hline Şahiner, 2008 & 1,211 & 0,671 & 1,772 & 2,04 & 1,98 \\
\hline Şanl1, 2009 & 1,190 & 0,597 & 1,784 & 1,76 & 1,92 \\
\hline Şirin, 2010 & 0,735 & $-0,10$ & 1,479 & 1,12 & 1,72 \\
\hline
\end{tabular}


Anadolu Journal of Educational Sciences International, January 2015, 5(1)

\begin{tabular}{|l|l|l|l|l|l|}
\hline Tankut, 2008 & 2,526 & 1,704 & 3,347 & 0,92 & 1,62 \\
\hline Ustaoğlu, 2012 & 1,740 & 1,114 & 2,365 & 1,58 & 1,88 \\
\hline Ünal, 2012 & 1,235 & 0,632 & 1,838 & 1,70 & 1,91 \\
\hline Ünlüer, 2008 & 0,339 & $-0,200$ & 0,879 & 2,13 & 1,99 \\
\hline Yeşiltaş, 2006 & 0,790 & 0,333 & 1,247 & 2,96 & 2,09 \\
\hline Yetkin, 2010 & 0,648 & 0,151 & 1,145 & 2,51 & 2,04 \\
\hline Yiğit, 2007 & 1,421 & 0,754 & 2,088 & 1,39 & 1,82 \\
\hline Yıldız, 2011 & 1,129 & 0,633 & 1,625 & 2,51 & 2,04 \\
\hline Yilmaz, 2006 & 1,834 & 1,204 & 2,463 & 1,56 & 1,87 \\
\hline
\end{tabular}

Tablo 2'de, analize dâhil edilen çalışmaların birleştirilmemiş etki büyüklükleri sunulmuştur. $\mathrm{Bu}$ bulgular birleştirilmiş etki büyüklüklerinin sunulmasına temel oluşturmuştur. Tablo incelendiğinde analize dâhil edilen çalışmaların etki büyüklüklerinin pozitif olduğu görülmektedir. Etki büyüklüklerinin pozitif çıkması deney gruplarının lehine bir sonuçtur. $\mathrm{Bu}$ nedenle, Sosyal Bilgiler dersinde öğretme-öğrenme sürecinde öğrenci merkezli yöntem, teknik, materyal ve yaklaşımları kullanmanın akademik başarı üzerinde etkili olduğu söylenebilir. Çalışmaların etki büyüklükleri değerlerinin Thalheimer ve Cook'a göre (2002) sınıflandırılması Tablo 3'te gösterilmiştir.

Tablo 3

Etki Büyüklüklerinin Sınıflandırılması

\begin{tabular}{lc}
\hline Etki büyüklüğü düzeyi & F \\
\hline$-0,15-0,15$ önemsiz düzey & 2 \\
\hline $0,15-0,40$ küçük düzey & 3 \\
\hline $0,40-0,75$ orta düzey & 8 \\
\hline $0,75-1,10$ geniş düzey & 9 \\
\hline $1,10-1,45$ çok geniş düzey & 14 \\
\hline 1,45 ve üzeri mükemmel düzey & 16 \\
\hline
\end{tabular}

Tablo incelendiğinde 16 çalışmanın mükemmel düzeyde etki büyüklügüne sahipken, 14 çalışmanın çok geniş düzeyde etki büyüklüğüne sahip olduğu görülmektedir. Çalışmalardan 3 tanesi küçük düzeyde etki büyüklüğüne sahipken, yalnızca 2 tanesi önemsiz düzeyde etki büyüklüğüne sahiptir. Araştırma kapsamına alınan 52 çalışmada öğrenci öğretim yöntemlerinin etkililiğine ilişkin sonuçlara modellere göre karşılaştırmalı olarak Tablo 4'de gösterilmiştir. 
Tablo 4

Etki modellerine meta-analiz çalışması sonuçlarının karşılaştırılması

\begin{tabular}{|c|c|c|c|c|c|c|c|c|}
\hline \multirow[b]{2}{*}{ Model } & \multirow[b]{2}{*}{ Z } & \multirow[b]{2}{*}{$N$} & \multirow[b]{2}{*}{2} & \multirow[b]{2}{*}{0} & \multirow[b]{2}{*}{ 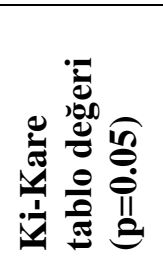 } & \multirow[b]{2}{*}{ 焉 } & \multicolumn{2}{|c|}{ Güven aralığgl } \\
\hline & & & & & & & $\stackrel{\Xi}{\Xi}$ & 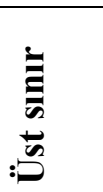 \\
\hline $\begin{array}{l}\text { Sabit etkiler } \\
\text { modeli }\end{array}$ & 52 & 29,139 & 0.000 & 272,681 & 68,67 & 1,170 & 1,091 & 1,249 \\
\hline $\begin{array}{l}\text { Rasgele etkiler } \\
\text { modeli }\end{array}$ & 52 & 13,303 & 0.000 & 272,681 & 68,67 & 1,246 & 1,063 & 1,430 \\
\hline
\end{tabular}

Tablo 4 incelendiğinde, sabit etkiler modeline göre \% 95'lik güven aralığının alt sınırı 1,091 ve üst sınırı 1,249; ortalama etki büyüklügü ise 1,170 olarak bulunmuştur. Bu etki büyüklüğü Thalheimer ve Cook'a göre (2002) çok geniş düzeyde etki olarak kabul edilmiştir. İstatistiksel anlamlılık amacıyla yapılan z testi hesapları sonucunda z puanı 29,139olarak bulunmuştur. $\mathrm{Bu}$ sonucun $\mathrm{p}=0.000$ ile istatistiksel açıdan anlamlı olduğu söylenebilir. Homojenlik testi sonucunda Q değeri 272,681 olarak hesaplanmıştır. Bu değerin ise $\chi 2$ tablosunda 51 serbestlik derecesinde 68,67 değerini aştığı görülmüştür (Laurencelle ve Dupuis, 2002). Buna göre etki büyüklükleri dağılımının heterojen olduğu belirlenmiştir. Homojenlik testi sonuçları kritik değerden yüksek çıktığı için rasgele etkiler modeli değerlendirilmiştir.

Tablo 4'te, rasgele etkiler modeline göre \% 95'lik güven aralığının alt 1,063 ve üst sınırı 1,430; ortalama etki büyüklüğü ise 1,246 olarak bulunmuştur. Bu etki büyüklüğü Thalheimer ve Cook'a göre (2002) çok geniş düzeyde etki olarak kabul edilmiştir. İstatistiksel anlamlılık amacıyla yapılan z testi hesapları sonucunda z puanı 13,303 olarak bulunmuştur. Bu sonucun p=0.000 ile istatistiksel açıdan anlamlı olduğu söylenebilir. Bu bağlamda, öğretme-öğrenme sürecinde kullanılan öğrenci merkezli öğretim yöntem, teknik, materyal ve yaklaşımların Sosyal Bilgiler dersinde akademik başarıyı artırmada daha etkili olduğu söylenebilir.

\section{Sonuç, Tartışma ve Öneriler}

2005 y1lında uygulanmaya başlanan Sosyal Bilgiler Öğretim Programı doğrultusunda öğretimde başarıyı artırmayı amaçlayan çok sayıda çalışma yapılmıştır. Öğrenci merkezli öğretme-öğrenme süreçlerinin akademik başarıya etkisini ortaya koymak amacıyla genellikle 
deneysel çalışmalar yapılmıştır. Bu araştırmada söz konusu deneysel çalışmalar meta-analiz yoluyla birleştirilmiştir. Bunun sonucunda çalışmaların etki büyüklükleri belirlenmiştir.

Araştırmada meta-analize toplam 52 çalışma dâhil edilmiştir. Çalışmaların çoğunluğu 2009 yılında yapılmıştır. En fazla çalışma Gazi Üniversitesi’nde gerçekleştirilmiştir. Bu çalışmaların büyük çoğunluğu yüksek lisans düzeyindeki çalışmalardır. Yine çalışmaların çoğunluğu 6. sınıf öğrencileriyle yapılmıştır. Araştırma kapsamına alınan çalışmalarda en fazla çoklu zekâ kuramının ele alındığı, bunu işbirliğine dayalı öğrenmenin takip ettiği görülmüştür. Çelik (2013) tarafından yapılan meta-analiz çalışmasında en fazla işbirliğine dayalı öğrenmenin ele alındığı görülmüştür.

Araştırmaya katılan çalışmaların tümünün akademik başarıya artırmada pozitif bir etkiye sahip olduğu görülmüştür. Çelik (2013) tarafından matematik dersinde alternatif yöntemlerin akademik başarıya etkisini inceleyen meta analiz çalışmasında da kapsama alınan çalışmalardan yalnızca 1 tanesinin negatif etkiye sahip olduğu görülmüştür.

Araştırma kapsamına alınan çalışmaların sabit etkiler modeline göre etki büyüklüğü 1,170 olarak bulunmuştur. Ancak homojenlik testi sonucunda Q değerinin kritik tablo değerini aşması sonucu etki büyüklüğü rasgele etkiler modeline değerlendirilmiştir. Rasgele etkiler modelinde etki büyüklüğü 1,246 olarak hesaplanmıştır. Bu etki büyüklügü Thalheimer ve Cook’a göre (2002) çok geniş düzeyde etki olarak sınıflanmıştır. Bu anlamda Sosyal Bilgiler dersinde kullanılan öğrenci merkezli öğretim yöntemlerinin öğrenci başarısını artırdığ sonucuna ulaşılabilir. Benzer biçimde Çelik (2013) ve Topan (2013) tarafindan yapılan metaanaliz çalışmasında da matematik dersinde kullanılan yöntemlerin öğrenci başarısını artırdığ sonucuna ulaşılmıştır. Ayrıca alanyazında yalnızca öğrenci öğretim yöntemlerinden birini ele alan meta analiz çalışmaları bulunmaktadır. Camnalbur (2008) ve Tomakin ve Yeşilyurt (2013) bilgisayar destekli öğretim, Gözüyeşil (2012) beyin temelli öğrenme, Dochy ve diğerleri (2003), Vernon ve Blake (1993) probleme dayalı öğrenme, Kablan, Topan ve Erkan (2013) materyal kullanımı, Okursoy Günhan (2009) kavram haritaları, Özdemirli (2011) ve Jonhnson, Johnson ve Stanne (2000) işbirliğine dayalı öğrenme yöntemlerinin daha etkili olduğunu yaptıkları meta analiz çalışmaları ile ortaya koymuşlardır. Bunlara ek olarak bu araştırmada da incelenen yöntem ve tekniklerin akademik başarı üzerindeki etkisinin deneysel araştırmalarla belirlendiği görülmüştür. 
Anadolu Journal of Educational Sciences International, January 2015, 5(1)

Araştırmada elde edilen sonuçlar bağlamında şu öneriler getirilebilir:

- Sosyal Bilgiler dersinde öğretmenler, başarıyı artırmak için öğrencileri etkin kılacak yöntem, teknik, materyal ve yaklaşımlardan yararlanabilir.

- $\mathrm{Bu}$ araştırma alt değişkenler belirlenerek tekrarlanabilir.

- Benzer araştırmalar farklı dersler için gerçekleştirilebilir.

\section{Kaynakça}

Akgöz, S., Ercan, İ., ve Kan, İ. (2004). Meta-analizi. Uludă̆ Üniversitesi Tıp Fakültesi Dergisi, 30(2), 107-112.

Avşar, Z., \& Alkış, S. (2007). İşbirlikli öğrenme yöntemi “Birleştirme I” tekniğinin sosyal bilgiler derslerinde öğrenci başarısına etkisi. Illköğretim Online, 6(2), 197-203.

Camnalbur, M. (2008). Bilgisayar destekli öğretimin etkililiği üzerine bir meta analiz çalışması. Yayımlanmamış yüksek lisans tezi, Marmara Üniversitesi, İstanbul.

Cohen, J. (1988). Statistical power analysis for the behavioral sciences. New York: Academic Pres.

Çelik, S. (2013). İlköğretim Matematik Derslerinde Kullanılan Alternatif Öğretim Yöntemlerinin Akademik Başarıya Etkisi: Bir Meta Analiz Çalışması. Yayımlanmamış yüksek lisans tezi. Eskişehir Osmangazi Üniversitesi, Eskişehir.

Deboer, G. E. (2002). Student-centered teaching in a standards-based world: Finding a sensible balance. Science \& Education, 11(4), 405-417.

Deveci, H. (2003). Sosyal bilgiler dersinde probleme dayalı öğrenmenin öğrencilerin derse ilişkin tutumlarına, akademik başarılarına ve hatırlama düzeylerine etkisi. Eskişehir: Anadolu Üniversitesi Yayınları.

Dewey, J. (2008). Okul ve toplum. Çev.: H. A. Başman. Ankara: Pegem Akademi Yayınları.

Dochy F., Segers M., Van Den Bossche P., Gijbels D. (2013). Effects of problem-based learning: a meta-analysis, Learning and Instruction, 13 (5), 533-568.

Duman, D., \& Şahiner, D. G. S. (2008). İlköğretim sosyal bilgiler dersinde aktif öğrenme tekniklerinin demokratik tutumlara ve ders başarısına etkisi. Buca Eğitim Fakültesi Dergisi, 24, 135-146. 
Anadolu Journal of Educational Sciences International, January 2015, 5(1)

Gözüyeşil, E. (2012). Beyin Temelli Öğrenmenin Akademik Başarıya Etkisi: Bir Meta-Analiz Çalışması. Yayımlanmamış yüksek lisans tezi. Niğde Üniversitesi, Niğde.

Gültekin, M. (2005). İlköğretim beşinci sınıf sosyal bilgiler dersinde proje tabanlı öğrenmenin öğrenme ürünlerine etkisi. Kuram ve Uygulamada Eğitim Bilimleri, 5(2), 517-556.

Gürdoğan Bayır, Ö. (2010). Sosyal Bilgilerde Güncel Olaylardan Yararlanmanın Öğrencilerin Eleştirel Düşünme Becerilerine Etkisi. Yayımlanmamış yüksek lisans tezi. Anadolu Üniversitesi, Eskişehir.

Johnson, D. W., Johnson, R. T. ve Stanne, M. B. (2000). Cooperative learning methods: a meta-analysis.

http://www.ccsstl.com/sites/default/files/Cooperative\%20Learning\%20Research\%20.pdf adresinden 31.10.2014 tarihinde edinilmiştir.

İbrahimoğlu, Z., \& Öztürk, C. (2013). Sosyal bilgiler dersinde örnek olay yöntemi kullanımının öğrencilerin akademik başarı derse karşı tutum ve eleştirel düşünme becerileri üzerine etkileri. Uludă̆ Üniversitesi Eğitim Fakültesi Dergisi, 26(2), 523-547.

Kablan, Z., Topan, B. ve Erkan, B. (2013). Sınıf İçi Öğretimde Materyal Kullanımının Etkililik Düzeyi: Bir Meta-Analiz Çalışması. Kuram ve Uygulamada Eğitim Bilimleri, 13(3), 1629-1644.

Laurencelle, L. ve Dupuis, F. A. (2002). Statistical tables, explained and applied. World Scientific Publishing: Singapore.

Maxim, G.W. (2006). Dynamic social studies for constructivist classrooms. 8th ed. Upper Saddle River, New Jersey: Pearson Education.

Obenchain, K.M. \& Morris, R.V. (2011). 50 social studies strategies for K-8 classrooms. 3rd ed. Boston: Pearson Education.

Okursoy Günhan, F. (2009). Kavram haritaları öğretim stratejisinin öğrenci başarısına etkisi: bir meta analiz çalışması. Yayımlanmamış yüksek lisans tezi. Marmara Üniversitesi, İstanbul.

Özcan, Ş. (2008). Eğitim yöneticisinin cinsiyet ve hizmetiçi eğitim durumunun göreve etkisi: Bir meta analitik etki analizi. Yayımlanmamış doktora tezi, Marmara Üniversitesi, İstanbul. 
Anadolu Journal of Educational Sciences International, January 2015, 5(1)

Özdemirli, G. (2011). İşbirlikli öğrenme yönteminin öğrencinin matematik başarısı ve matematiğe ilişkin tutumu üzerindeki etkililiği: bir meta-analiz çalışması. Yayımlanmamış yüksek lisans tezi. Çukurova Üniversitesi, Fen Bilimleri Enstitüsü, Adana.

Russell, W. (2010). Teaching social studies in the 21st century: a research study of secondary social studies teachers' instructional methods and practices. Action in Teacher Education, $32(1), 65-72$.

Sağlam, M., ve Yüksel, İ. (2007). Program değerlendirmede meta-analiz ve metadeğerlendirme yöntemleri. Dumlupınar Üniversitesi Sosyal Bilimler Dergisi, 18, 175188.

Schmidt, L. (2007). Social studies that sticks. Portsmouth, NH: Heinemann.

Seefeldt, C., Castle, S. \& Falconer, R.C. (2010). Social studies for the preschool/primary child. 8th ed. Upper Saddle River, New Jersey: Pearson Education.

Şahin, M. C. (2005). İnternet tabanlı uzaktan eğitimin etkililiği: Bir meta-analiz çalışması. Yayımlanmamış yüksek lisans tezi, Çukurova Üniversitesi, Adana.

Thalheimer, W. ve Cook, S. (2002). How to calculate effect size from published research: a simplified methodology. psyphz.psych.wisc.edu/ shackman/Effect_Sizes_Spreadsheet.xls adresinden 24.10.2014 tarihinde edinilmiştir.

Tomakin, E. ve Yeşilyurt, M. (2013). Bilgisayar destekli yabancı dil öğretim çalışmalarının meta analizi: Türkiye örneği. Yüzüncü Yll Üniversitesi Eğitim Fakültesi Dergisi, 10(1), 248-263.

Topan, B. (2013). Matematik öğretiminde öğrenci merkezli yöntemlerin akademik başarı ve derse yönelik tutum üzerindeki etkililiği: bir meta-analiz çalışması. Yayımlanmamış yüksek lisans tezi, Kocaeli Üniversitesi, Kocaeli.

Topçu, P. (2009). Cinsiyetin bilgisayar tutumu üzerine etkisi: bir meta analiz çalışması. Yayımlanmamış yüksek lisans tezi, Marmara Üniversitesi, İstanbul.

Ünal, Ç., \& Çelikkaya, T. (2009). Yapılandırmacı Yaklaşımın Sosyal Bilgiler Öğretiminde Başarı, Tutum ve Kalıcılığa Etkisi (5. Sınıf Örneği). Atatürk Üniversitesi Sosyal Bilimler Enstitüsü Dergisi, 13(2). 
Üstün, U. (2012). To what extent is problem-based learning effective as compared to traditional teaching in science education? A meta-analysis study. Yayımlanmamış doktora tezi, Orta Doğu Teknik Üniversitesi, Ankara.

Vernon, D. T., \& Blake, R. L. (1993). Does problem-based learning work? a meta-analysis of evaluative research. Academic Medicine, 68(7) http://eric.ed.gov/?id=EJ467208 adresinden 31.10.2014 tarihinde edinilmiştir.

Yaşar, Ş. (2012). Yapılandırmacı anlayış ve ilköğretim birinci kademe programlarına etkileri. Öğretmenlik meslek bilgisi alanındaki gelişmeler. Ed. A. Hakan. (s.61-79). Eskişehir: Anadolu Üniversitesi Yayınları.

Y1lmaz, K. (2009). Democracy through learner-centered education: A Turkish perspective. International Review of Education, 55(1), 21-37.

\section{EK 1 Çalışma Künyeleri}

\begin{tabular}{|c|c|c|c|}
\hline Yazar & Yll & Çalışmanın Adı & Yapıldığı Üniversite \\
\hline Elif Aladağ & 2007 & $\begin{array}{l}\text { İlköğretim 7. Sınıf Sosyal Bilgiler Dersinde Coğrafi } \\
\text { Bilgi Sistemleri Kullanımının Öğrencilerin Akademik } \\
\text { Başarı ve Derse Karşı Motivasyonlarına Etkisi }\end{array}$ & Gazi Üniversitesi \\
\hline Gözde Alkan & 2010 & $\begin{array}{l}\text { Sosyal Bilgiler Öğretiminde Kavram Karikatürlerinin } \\
\text { Öğrenci Başarısına Etkisi }\end{array}$ & Niğde Üniversitesi \\
\hline Adem Ateş & 2007 & $\begin{array}{l}\text { Çoklu Zekâ Kuramına Göre Düzenlenen İlköğretim } 7 . \\
\text { Sınıf Sosyal Bilgiler Dersi “Osmanlı Kültür ve } \\
\text { Uygarlığı” Ünitesi İçin Hazırlanan Eğitim Durumunun } \\
\text { Öğrencilerin Akademik Başarısına Etkisi }\end{array}$ & $\begin{array}{l}\text { Karadeniz Teknik } \\
\text { Üniversitesi }\end{array}$ \\
\hline $\begin{array}{c}\text { Esra Yavuz } \\
\text { Avcı }\end{array}$ & 2009 & $\begin{array}{l}\text { İlköğretim 5.Sınıf Sosyal Bilgiler Dersinde Oluşturmacı } \\
\text { Öğrenme Yaklaşımının Öğrencilerin Başarı Düzeylerine } \\
\text { ve Derse Yönelik Tutumlarına Etkisi }\end{array}$ & Uludağ Üniversitesi \\
\hline Serkan Avşar & 2010 & $\begin{array}{l}\text { İlköğretim İkinci Kademe Sosyal Bilgiler Derslerinde } \\
\text { Coğrafya Konularının Öğretiminde Materyal } \\
\text { Kullanımının Öğrenci Başarısına Etkisi }\end{array}$ & Selçuk Üniversitesi \\
\hline $\begin{array}{l}\text { Hülya Ayaz } \\
\text { Can }\end{array}$ & 2005 & $\begin{array}{l}\text { Altı Şapkalı Düşünme Tekniğinin Sosyal Bilgiler } \\
\text { Dersinde Öğrenci Başarısına Etkisi }\end{array}$ & Firat Üniversitesi \\
\hline $\begin{array}{l}\text { Murtaza } \\
\text { Aykaç }\end{array}$ & 2008 & $\begin{array}{l}\text { Sosyal Bilgiler Dersinde Yaratıcı Dramının Yöntem } \\
\text { Olarak Kullanılmasının Öğrenci Başarısına Etkisi }\end{array}$ & Ankara Üniversitesi \\
\hline Şevki Babacan & 2006 & $\begin{array}{l}\text { Sosyal Bilgiler 6. Sınıf Coğrafya Ünitelerinden } \\
\text { "Türkiye'miz”in Öğretiminde İşbirlikli Yöntem Destekli } \\
\text { Çoklu Zekâ Kuramının Erişiye Etkisi }\end{array}$ & $\begin{array}{c}\text { Çanakkale Onsekiz } \\
\text { Mart Üniversitesi }\end{array}$ \\
\hline İkram Bağc1 & 2009 & $\begin{array}{l}\text { İlköğretim Sosyal Bilgiler Dersinde Türk Tarihinde } \\
\text { Yolculuk Ünitesinin Alternatif Değerlendirme } \\
\text { (Portfolyo ) ile İşlenmesinin Öğrenci Başarısı ve } \\
\text { Tutumuna Etkisi }\end{array}$ & Gazi Üniversitesi \\
\hline Sultan Bulut & 2010 & $\begin{array}{l}\text { Aktif Öğrenme Tekniklerinin İlköğretim 4. Sınıf } \\
\text { Öğrencilerinin Sosyal Bilgiler Dersi Üretimden } \\
\text { Tüketime Ünitesini Öğrenme Başarılarına Etkisi }\end{array}$ & Gazi Üniversitesi \\
\hline $\begin{array}{l}\text { Hüseyin } \\
\text { Çalışkan }\end{array}$ & 2008 & $\begin{array}{l}\text { İlköğretim 7. Sınıf Sosyal Bilgiler Dersinde Araştırmaya } \\
\text { Dayalı Öğrenme Yaklaşımının Derse Yönelik Tutuma, }\end{array}$ & Gazi Üniversitesi \\
\hline
\end{tabular}




\begin{tabular}{|c|c|c|c|}
\hline & & Akademik Başarıya ve Kalıcılık Düzeyine Etkisi & \\
\hline $\begin{array}{l}\text { Findık } \\
\text { Çalışkan }\end{array}$ & 2005 & $\begin{array}{l}\text { İlköğretim 4. Sınıf Sosyal Bilgiler Dersinde Aktif } \\
\text { Öğrenme Yöntemlerinden Çözümlemeli Öykü } \\
\text { Yönteminin Öğrencilerin Akademik Başarılarına, } \\
\text { Tutumlarına ve Aktif Öğrenme Düzeylerine Etkisi }\end{array}$ & $\begin{array}{l}\text { Mustafa Kemal } \\
\text { Üniversitesi }\end{array}$ \\
\hline $\begin{array}{l}\text { Celalettin } \\
\text { Çelebi }\end{array}$ & 2006 & $\begin{array}{l}\text { Yapılandırmacılık Yaklaşımına Dayalı İşbirlikli } \\
\text { Öğrenmenin İlköğretim 5. Sınıf Sosyal Bilgiler Dersinde } \\
\text { Öğrencilerin Erişi ve Tutumlarına Etkisi }\end{array}$ & Selçuk Üniversitesi \\
\hline Tuba Çengelci & 2005 & $\begin{array}{l}\text { Sosyal Bilgiler Dersinde Beyin Temelli Öğrenmenin } \\
\text { Akademik Başarıya ve Kalıcıllı̆g Etkisi }\end{array}$ & Anadolu Üniversitesi \\
\hline $\begin{array}{l}\text { Sabahattin } \\
\text { Çiftçi }\end{array}$ & 2006 & $\begin{array}{l}\text { Sosyal Bilgiler Öğretiminde Proje Tabanlı Öğrenmenin } \\
\text { Öğrencilerin Akademik Risk Alma Düzeylerine, } \\
\text { Problem Çözme Becerilerine, Erişilerine Kalıcılığa ve } \\
\text { Tutumlarına Etkisi }\end{array}$ & Selçuk Üniversitesi \\
\hline $\begin{array}{l}\text { İskender } \\
\text { Daşdemir }\end{array}$ & 2013 & $\begin{array}{l}\text { Sosyal Bilgiler Öğretiminde Coğrafi Bilgi Sistemleri } \\
\text { Kullanımının Öğrencilerin Akademik Başarısına Etkisi }\end{array}$ & $\begin{array}{l}\text { Muğla Sitkı Koçman } \\
\text { Üniversitesi } \\
\end{array}$ \\
\hline $\begin{array}{l}\text { Nergiz Fatma } \\
\text { Erdoğan }\end{array}$ & 2009 & $\begin{array}{l}\text { İlköğretim Sosyal Bilgiler Öğretiminde Proje Tabanlı } \\
\text { Öğrenme Yönteminin Ders Başarısına ve Sınıf } \\
\text { Atmosferine Etkisi }\end{array}$ & $\begin{array}{l}\text { Dokuz Eylül } \\
\text { Üniversitesi }\end{array}$ \\
\hline $\begin{array}{l}\text { Zehra Nur } \\
\text { Ersözlü }\end{array}$ & 2008 & $\begin{array}{l}\text { Yansıtıcı Düşünmeyi Geliştirici Etkinliklerin İlköğretim } \\
\text { 5. Sınıf Öğrencilerinin Sosyal Bilgiler Dersindeki } \\
\text { Akademik Başarılarına ve Tutumlarına Etkisi }\end{array}$ & Firat Üniversitesi \\
\hline $\begin{array}{l}\text { Mehmet } \\
\text { Eskitürk }\end{array}$ & 2009 & $\begin{array}{l}\text { Sosyal Bilgiler Dersinde Eleştirel Düşünme Becerilerini } \\
\text { Temel Alan İşbirlikli Öğrenme Etkinliklerinin } \\
\text { Akademik Başarı Düzeyine Etkisi }\end{array}$ & $\begin{array}{l}\text { Çanakkale Onsekiz } \\
\text { Mart Üniversitesi }\end{array}$ \\
\hline Şule Firat & 2008 & $\begin{array}{l}\text { İlköğretim 4. Sınıf Öğrencilerinin Sosyal Bilgiler } \\
\text { Dersine Yönelik Akademik Başarıları Üzerinde Proje } \\
\text { Tabanlı Öğrenme Yaklaşımının Etkisi }\end{array}$ & İnönü Üniversitesi \\
\hline $\begin{array}{l}\text { Beytullah } \\
\text { Göçmen }\end{array}$ & 2007 & $\begin{array}{l}\text { İlköğretim 4.Sınıf Sosyal Bilgiler Derslerinde Bilgiyi } \\
\text { Kullanılabilir Biçimlerde Planlama ve Yazma } \\
\text { Becerilerinin Geliştirilmesinin Öğrencilerin Öğrenme ve } \\
\text { Hatırlama Düzeyine Etkisi }\end{array}$ & Gazi Üniversitesi \\
\hline $\begin{array}{l}\text { Mustafa } \\
\text { Gökgöz }\end{array}$ & 2010 & $\begin{array}{l}\text { İlköğretim 5. Sınıf Sosyal Bilgiler Dersinde Buluş } \\
\text { Yoluyla Öğrenmenin Akademik Başarıya Etkisi }\end{array}$ & $\begin{array}{c}\text { Zonguldak } \\
\text { Karaelmas } \\
\text { Üniversitesi }\end{array}$ \\
\hline $\begin{array}{l}\text { Özlem Gülden } \\
\text { Göncüoğlu }\end{array}$ & 2010 & $\begin{array}{l}\text { 6. Sınıf Sosyal Bilgiler Dersi Demokrasinin Serüveni } \\
\text { Ünitesinin Ögretiminde Drama ve İşbirlikli Öğretim } \\
\text { Yöntemlerinin Öğrenci Tutum ve Başarısına Etkisi }\end{array}$ & Niğde Üniversitesi \\
\hline $\begin{array}{l}\text { Hacı Murat } \\
\text { Görer }\end{array}$ & 2008 & $\begin{array}{l}\text { İlköğretim 6. Sınıf Sosyal Bilgiler Dersi Ülkemizin } \\
\text { Kaynakları Ünitesinde Uygulanan Çoklu Zekâ } \\
\text { Kuramının Öğrencilerin Akademik Başarılarına ve } \\
\text { Tutumlarına Etkisi }\end{array}$ & Yeditepe Üniversitesi \\
\hline Uğur Gülsoy & 2010 & $\begin{array}{l}\text { İlköğretim Birinci Kademede Aktif Öğrenmenin Sosyal } \\
\text { Bilgiler Dersinde Uygulanmasının Öğrenci Başarısına ve } \\
\text { Tutumlarına Etkisi }\end{array}$ & Selçuk Üniversitesi \\
\hline $\begin{array}{c}\text { Hidir } \\
\text { Karaduman }\end{array}$ & 2005 & $\begin{array}{l}\text { Sosyal Bilgiler Dersinde Yapılandırmacı Öğrenme } \\
\text { İlkelerine Göre Hazırlanan Öğretim Materyallerinin } \\
\text { Öğrencilerin Derse İlişkin Tutumlarına, Başarılarına ve } \\
\text { Hatırlama Düzeylerine Etkisi }\end{array}$ & Anadolu Üniversitesi \\
\hline İsa Karakoç & 2006 & $\begin{array}{l}\text { İlköğretim İkinci Kademe Sosyal Bilgiler Dersi Coğrafya } \\
\text { Konularının Öğretiminde Çoklu Zekâ Uygulamalarının } \\
\text { Akademik Başarı ve Tutuma Etkisi }\end{array}$ & Niğde Üniversitesi \\
\hline Tayfun Kartal & 2009 & $\begin{array}{l}\text { İlköğretim 6. Sınıf Sosyal Bilgiler Dersi İlkçağ Tarihi } \\
\text { Konularının Öğretiminde Drama Yönteminin Öğrenci } \\
\text { Başarısına Etkisi }\end{array}$ & Selçuk Üniversitesi \\
\hline Nilgün Kaya & 2009 & $\begin{array}{l}\text { Sosyal Bilgiler Öğretiminde İnteraktif (Etkileşimli) } \\
\text { Bilgisayar Destekli Öğretimin Öğrenci Başarısına Etkisi }\end{array}$ & Yeditepe Üniversitesi \\
\hline $\begin{array}{l}\text { Mustafa Şaban } \\
\text { Keser }\end{array}$ & 2012 & $\begin{array}{l}\text { Sosyal Bilgiler Dersinde Bilgisayar Destekli Eğitimin } \\
\text { Akademik Başarıya Etkisi }\end{array}$ & Aksaray Üniversitesi \\
\hline
\end{tabular}




\begin{tabular}{|c|c|c|c|}
\hline Seçil Kıy Can & 2010 & $\begin{array}{l}\text { İlköğretim 4. ve 5. Sınıflarda Sosyal Bilgiler Dersinde } \\
\text { (Araç-Gereç) Materyal Kullanımının Öğrenci Başarısına } \\
\text { Etkisi (Kars İli Örneği) }\end{array}$ & Kafkas Üniversitesi \\
\hline İsmail Koç & 2008 & $\begin{array}{l}\text { Çoklu Zeka Kuramına Dayalı Olarak Gerçekleştirilen } \\
\text { Proje Tabanlı Öğrenmenin Öğrencilerin 7. Sınıf Sosyal } \\
\text { Bilgiler Dersindeki Tutum ve Erişilerine Etkisi }\end{array}$ & Selçuk Üniversitesi \\
\hline $\begin{array}{l}\text { Hasan } \\
\text { Hüseyin } \\
\text { Mergen }\end{array}$ & 2011 & $\begin{array}{l}\text { İlköğretim 5.Sınıf Sosyal Bilgiler Dersinde Öğrenme } \\
\text { İstasyonları Uygulamasının Akademik Başarıya ve } \\
\text { Kalıcılığa Etkisi }\end{array}$ & $\begin{array}{l}\text { Afyon Kocatepe } \\
\text { Üniversitesi }\end{array}$ \\
\hline $\begin{array}{l}\text { Ümmühan } \\
\text { Öner }\end{array}$ & 2007 & $\begin{array}{l}\text { İlköğretim 7. Sınıf Sosyal Bilgiler Dersi Tarih } \\
\text { Konularının Öğretiminde İşbirlikli Öğrenme Yönteminin } \\
\text { Öğrenci Başarısına Etkisi }\end{array}$ & Firat Üniversitesi \\
\hline Turgay Öntaş & 2010 & $\begin{array}{l}\text { İlköğretim Sosyal Bilgiler Dersinde Yapılandırmacı } \\
\text { Yaklaşım ile Dizgeli Eğitimin Öğrenci Erişisine Etkisi } \\
\text { Arasındaki Fark }\end{array}$ & $\begin{array}{l}\text { Hacettepe } \\
\text { Üniversitesi }\end{array}$ \\
\hline İsmail Özkan & 2009 & $\begin{array}{l}\text { Gezi-Gözlem ve İnceleme Yönteminin 6.Sınıf Sosyal } \\
\text { Bilgiler Programı Ülkemizin Kaynakları Ünitesindeki } \\
\text { Öğrenci Başarılarına Etkisi }\end{array}$ & $\begin{array}{l}\text { Abant İzzet Baysal } \\
\text { Üniversitesi }\end{array}$ \\
\hline Talip Öztürk & 2011 & $\begin{array}{l}\text { Sosyal Bilgiler Öğretiminde Projeye Dayalı Öğrenme } \\
\text { Yaklaşımının Öğrencilerin Başarısına, Derse Yönelik } \\
\text { Tutumlarına ve Görüşlerine Etkisi }\end{array}$ & Gazi Üniversitesi \\
\hline Nihan Salur & 2009 & $\begin{array}{l}\text { Sosyal Bilgiler Dersinde Rol Yapma Yöntemini } \\
\text { Kullanmanın İlkögrretim 5.Sınıf Öğrencilerinin Sosyal } \\
\text { Zekâ Gelişim Düzeylerine ve Akademik Başarılarına } \\
\text { Etkisi }\end{array}$ & $\begin{array}{l}\text { Dokuz Eylül } \\
\text { Üniversitesi }\end{array}$ \\
\hline İbrahim Sarı & 2007 & $\begin{array}{l}\text { Sosyal Bilgiler Öğretiminde Sözlü Tarih Etkinliklerinin } \\
\text { Öğrenci Başarı, Beceri ve Tutumlarına Etkisi }\end{array}$ & Gazi Üniversitesi \\
\hline $\begin{array}{l}\text { Mustafa } \\
\text { Sarıtepeci }\end{array}$ & 2012 & $\begin{array}{l}\text { İlköğretim 7. Sınıf Sosyal Bilgiler Dersinde } \\
\text { Harmanlanmış Öğrenme Ortamlarının Öğrencilerin } \\
\text { Derse Katılımına, Akademik Başarısına, Derse Karşı } \\
\text { Tutumuna ve Motivasyonuna Etkisi }\end{array}$ & Gazi Üniversitesi \\
\hline $\begin{array}{c}\text { Derya Gül } \\
\text { Sinem Şahiner }\end{array}$ & 2008 & $\begin{array}{l}\text { İlköğretim Sosyal Bilgiler Dersinde Aktif Öğrenme } \\
\text { Tekniklerinin Demokratik Tutumlara ve Ders Başarısına } \\
\text { Etkisi }\end{array}$ & $\begin{array}{l}\text { Dokuz Eylül } \\
\text { Üniversitesi }\end{array}$ \\
\hline Mehmet Şanlı & 2009 & $\begin{array}{l}\text { Sosyal Bilgiler Dersi Tarih Konularının Öğretiminde } \\
\text { Siyasetnamelerden Faydalanmanın Akademik Başarıya } \\
\text { Etkisi }\end{array}$ & $\begin{array}{l}\text { Gaziosmanpaşa } \\
\text { Üniversitesi }\end{array}$ \\
\hline Ömer Şirin & 2010 & $\begin{array}{l}\text { Çoklu Zekâ Uygulamalarının Sosyal Bilgiler Dersinde } \\
\text { Öğrencilerin Akademik Başarısına Etkisi }\end{array}$ & Firat Üniversitesi \\
\hline $\begin{array}{l}\text { Ülkü Seda } \\
\text { Tankut }\end{array}$ & 2008 & $\begin{array}{l}\text { İköğretim 7. Sınıf Sosyal Bilgiler Dersinde Bilgisayar } \\
\text { Destekli Öğretimin Akademik Başarıya ve Kalıcılığa } \\
\text { Etkisi }\end{array}$ & $\begin{array}{l}\text { Çukurova } \\
\text { Üniversitesi }\end{array}$ \\
\hline $\begin{array}{l}\text { Aydan } \\
\text { Ustaoğlu }\end{array}$ & 2012 & $\begin{array}{l}\text { İlköğretim 7. Sınıf Sosyal Bilgiler Dersi Türk Tarihinde } \\
\text { Yolculuk Ünitesinde Sanal Müzelerin Kullanımının } \\
\text { Öğrenci Başarısına Etkisi }\end{array}$ & Gazi Üniversitesi \\
\hline Barış Ünal & 2012 & $\begin{array}{l}\text { Coğrafi Bilgi Sistemleri (Cbs) Destekli Sosyal Bilgiler } \\
\text { Dersi Öğretiminin Öğrenci Başarısı ve Tutumuna Etkisi }\end{array}$ & Akdeniz Üniversitesi \\
\hline $\begin{array}{l}\text { Gülbeyaz } \\
\text { Ünlüer }\end{array}$ & 2008 & $\begin{array}{l}\text { Sosyal Bilgiler Dersinde Gazete Kullanımının } \\
\text { Öğrencilerin Akademik Başarılarına ve Tutumlarına } \\
\text { Etkisi }\end{array}$ & Anadolu Üniversitesi \\
\hline Erkan Yeşiltaş & 2006 & $\begin{array}{l}\text { Sosyal Bilgiler Öğretimine Yönelik Geliştirilen } \\
\text { Bilgisayar Yazılımının Akademik Başarı ve Tutuma } \\
\text { Etkisi }\end{array}$ & Gazi Üniversitesi \\
\hline $\begin{array}{l}\text { Tuba } \\
\text { Özkümüş } \\
\text { (Yetkin) }\end{array}$ & 2010 & $\begin{array}{l}\text { İlköğretim 4. Sınıf Sosyal Bilgiler Öğretiminde İşbirlikli } \\
\text { Öğrenme Yönteminin Öğrencilerin Akademik } \\
\text { Başarılarına ve Derse Yönelik Tutumlarına Etkisi }\end{array}$ & Gazi Üniversitesi \\
\hline $\begin{array}{l}\text { E. Özlem } \\
\text { Yiğit }\end{array}$ & 2007 & $\begin{array}{l}\text { Öyküleştirme Yönteminin 6. Sınıf Sosyal Bilgiler } \\
\text { Programı Ülkemizin Kaynakları Ünitesindeki Öğrenci } \\
\text { Başarısı Üzerine Etkisi }\end{array}$ & $\begin{array}{l}\text { Abant İzzet Baysal } \\
\text { Üniversitesi }\end{array}$ \\
\hline
\end{tabular}




\begin{tabular}{|c|c|c|c|}
\hline Bahar Yıldız & 2011 & $\begin{array}{l}\text { Harmanlanmış Öğrenme Ortamlarının İlköğretim 7.Sınıf } \\
\text { Sosyal Bilgiler Dersindeki Akademik Başarıya Etkisi }\end{array}$ & $\begin{array}{l}\text { Celal Bayar } \\
\text { Üniversitesi }\end{array}$ \\
\hline Olcay Yilmaz & 2006 & $\begin{array}{l}\text { İlköğretim 7. Sınıf Sosyal Bilgiler Dersinde "Proje } \\
\text { Tabanlı Öğrenme"nin Öğrenenlerin Akademik } \\
\text { Başarıları, Yaratıcılıkları ve Tutumlarına Etkisi }\end{array}$ & $\begin{array}{c}\text { Zonguldak } \\
\text { Karaelmas } \\
\text { Üniversitesi }\end{array}$ \\
\hline
\end{tabular}

\section{EXTENDED ABSTRACT}

Social studies integrates content of social sciences to teach necessary knowledge, skills, and values for training active citizens of democratic society. Constructivist approach which requires students construct their own meaning and understanding in social environment may contribute teaching-learning process of the Social Studies course. It seems important to investigate effect of constructivist methods, active learning methods, technological tools, and assessment methods on students' academic achievement to improve teaching-learning process. In the related literature, it is seen that many studies were conducted to analyze effect of student-centered methods on students' academic achievement. However, these studies were not analyzed together to determine their effect on academic achievement in the Social Studies course. The present study aimed to analyze the effect of student-centered teaching process on academic achievement in the Social Studies course via meta-analysis method. The study also intended to contribute to the development of teaching-learning process of the Social Studies course. Studies focus on constructivist approach and its teaching methods as cooperative learning, and project-based learning were included in meta-analysis. Moreover studies about brain-based learning, multiple intelligence theory, discovery learning, blended learning, inquiry-based learning, active learning and computer assisted learning were examined in meta-analysis process. Data of the study were obtained from 52 Master and $\mathrm{PhD}$ theses which were submitted to the YÖK National Digital Thesis/Dissertation Archives after 2005 in Turkey. Comprehensive Meta-Analysis (CMA) software was used to conduct the metaanalysis. The present study used "study effect" meta-analysis for the analysis of the data. Findings of the study revealed that student-centered teaching approaches, methods, techniques, and materials had a positive effect on academic achievement in the Social Studies course. It can be claimed that student-centered teaching methods, techniques, materials and approaches help increase academic achievement in the Social Studies course. 